\title{
Carbon monoxide levels in the breath of smokers and nonsmokers: effect of domestic heating systems
}

\author{
B D COX AND MARGARET J WHICHELOW
}

From the Office of the Regius Professor of Physic, Cambridge University School of Clinical Medicine, Addenbrooke's Hospital, Hills Road, Cambridge CB2 2QQ

SUMMARY Breath and ambient (room) carbon monoxide ( $\mathrm{CO}$ ) levels were measured in a random sample of 168 adults in their own homes. The levels of breath $\mathrm{CO}$ in the 69 smokers ranged from $3 \mathrm{ppm}$ to over $100 \mathrm{ppm}, 74 \%$ being above $10 \mathrm{ppm}$; mean levels in the 99 nonsmokers were lower than in the smokers, $79 \%$ being below $6 \mathrm{ppm}$. In the remaining $21 \%$ of nonsmokers with higher breath levels than expected, the ambient $\mathrm{CO}$ was also found to be elevated, ranging up to $38 \mathrm{ppm}$. A close correlation in the nonsmokers was found between the breath and ambient $\mathrm{CO}$ levels $(\mathrm{r}=0.952, \mathrm{p}<0.001)$. The rooms with the elevated ambient $\mathrm{CO}$ levels (above $5 \mathrm{ppm})$ were those which, at the time of testing, were being heated by gas radiant heaters, open fires or stoves. The maximum ambient $\mathrm{CO}$ in the rooms of smokers with non $\mathrm{CO}$ generating heating was $16 \mathrm{ppm}$. The results suggest that many people, both smokers and nonsmokers, may be at risk from $\mathrm{CO}$ generated by certain domestic heating systems and that nonsmokers are far more likely to be exposed to high levels of $\mathrm{CO}$ from these sources than from being in a room with a heavy smoker. Poor ventilation associated with the current trend towards excluding all draughts is likely to exacerbate the situation for both smokers and nonsmokers.

As a precursor to a nationwide study of various factors affecting health and health attitudes, two pilot studies were carried out on a random sample of adults. Included in these surveys, which were conducted in the subjects' own homes, were measurements of breath carbon monoxide. Carbon monoxide $(\mathrm{CO})$ levels in breath correlate well with carboxyhaemoglobin in the blood ${ }^{1}$ and have been used as an indicator of a smoker. ${ }^{12}$ In the present studies, it was planned to use the breath $\mathrm{CO}$ measurements as a check on the subjects' reported smoking habits. It soon became evident that the simultaneous measurement of environmental $\mathrm{CO}$ was also necessary, when the levels of $\mathrm{CO}$ in the breath of some nonsmokers far exceeded the anticipated low values. ${ }^{23}$ This may be important in view of the government's recent decision to publish the $\mathrm{CO}$ content of cigarettes, and the current interest in the possible health hazards of chronic $\mathrm{CO}$ exposure. ${ }^{4}$

\section{Methods}

The subjects comprised 86 men and 82 women chosen at random from the electoral registers of
Bristol, Avon, and Bury St Edmunds, Suffolk. Their ages ranged from 18 to 74 years. The selections were made from electoral wards which had a distribution of socioeconomic groups similar to that existing in the United Kingdom as a whole.

The equipment used for the measurement of $\mathrm{CO}$ was a battery powered portable Ecolyzer (supplied by Analysis Automation Ltd) which will detect $\mathrm{CO}$ levels down to a concentration of less than one part per million.

The estimations were made in the subjects' own homes in the room in which the interview was being conducted (usually the sitting room).

The type of heating system in operation was noted. A measurement of the ambient $\mathrm{CO}$ level was made and after this the subject took a deep breath and held it for 20 seconds (to allow for equilibration with the $\mathrm{CO}$ concentration in the blood) and then blew into a trilaminate plastic bag which was subsequently attached to the sampling port of the Ecolyzer. The $\mathrm{CO}$ concentration in the expired air was measured and recorded. If the subject was a smoker, the time of the last cigarette and the number of cigarettes smoked per day were noted. 


\section{Results}

The levels of breath $\mathrm{CO}$ relative to ambient $\mathrm{CO}$ found in the population studied are shown in fig 1 for the 99 nonsmokers and in fig 2 for the 69 smokers (of whom 66 were cigarette smokers). The breath $\mathrm{CO}$ levels of the smokers were in general higher than those of the nonsmokers, ranging from 3 to more than $100 \mathrm{ppm}$, only $6 \%$ of smokers having breath CO levels lower than $6 \mathrm{ppm}$ and $74 \%$ having levels above $10 \mathrm{ppm}$. Although most $(79 \%)$ of the nonsmokers had levels below $6 \mathrm{ppm}, 12 \%$ had levels above $10 \mathrm{ppm}$. The range for the nonsmokers was 2-60 ppm.

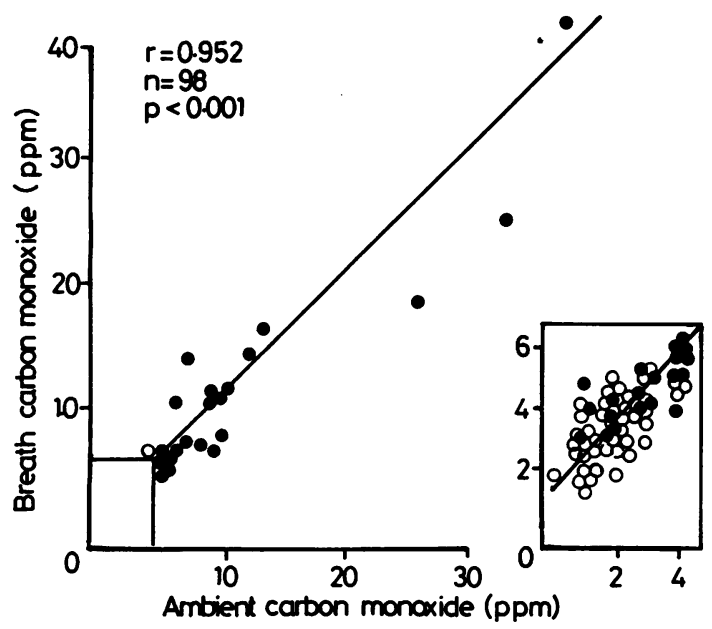

Fig 1 Relation between breath and ambient (room) carbon monoxide levels in nonsmokers, in rooms with non $\mathrm{CO}$ generating heating (O) and possible $\mathrm{CO}$ generating heating (O), with calculated regression line.

Ambient $\mathrm{CO}$ levels in the respondents' homes were found to range from 0 to $42 \mathrm{ppm}$. The higher ambient $\mathrm{CO}$ levels were found in rooms where certain types of heating were operating: radiant gas fires (particularly if the gas fire was turned down low and was of the type where the element was then no longer incandescent), open coal or wood fires, coal or wood stoves, and paraffin heaters. Rooms being heated with these types of heating were designated $\mathrm{CO}$ generating (fig 3 ). Low ambient $\mathrm{CO}$ levels were almost always found in rooms where there was no heating on, or where the heating was by water or oil filled radiator or electric fire-non $\mathrm{CO}$ generating heating (fig 3 ). In nonsmokers, there was a very close correlation $(\mathrm{r}=0.952, \mathrm{p}<0.001)$ between the

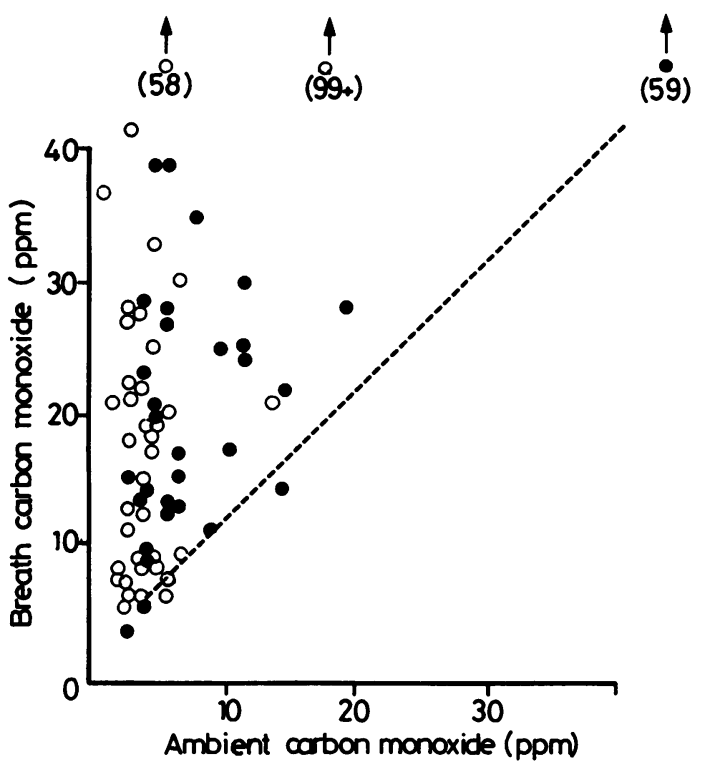

Fig 2 Relation between breath and ambient (room) carbon monoxide levels in smokers, in rooms with non $\mathrm{CO}$ generating heating $(\mathrm{O})$ and possible $\mathrm{CO}$ generating heating (O), compared with the regression line for nonsmokers.

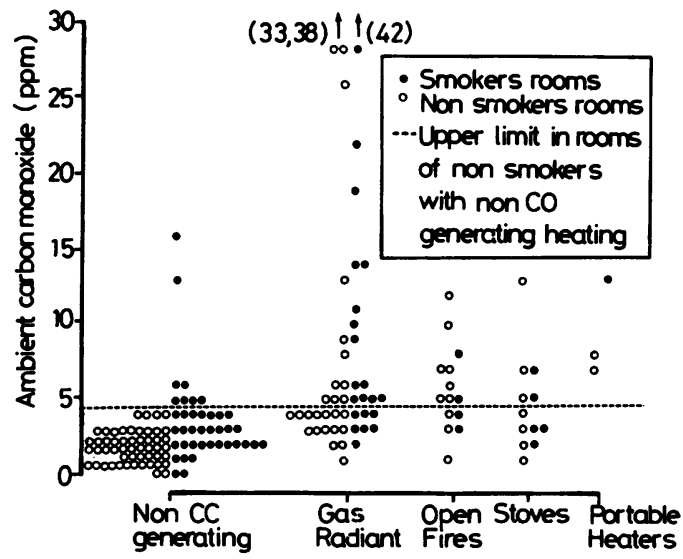

Fig 3 Levels of ambient carbon monoxide in rooms of smokers (O) and nonsmokers (O) with various types of heating. "Non $\mathrm{CO}$ generating" includes rooms with no heating operating. 
ambient $\mathrm{CO}$ and the breath $\mathrm{CO}$ (fig 1). The regression coefficient of 1.03 shows that for a rise of $1 \mathrm{ppm} \mathrm{CO}$ in the atmosphere there was an almost equal rise of $\mathrm{CO}$ in the breath of nonsmokers. The regression intercept with the abcissa indicates that breath $\mathrm{CO}$ levels are $1.5 \mathrm{ppm}$ higher at all levels than the ambient. The $1.5 \mathrm{ppm} C O$ difference reflects in vivo metabolic production of $\mathrm{CO}^{3}$ The nonsmoker with the highest breath $\mathrm{CO}$ of $60 \mathrm{ppm}$ in an ambient atmosphere of $3 \mathrm{ppm}$ was excluded from the analysis as he was a welder using gas welding equipment who had just arrived home from work.

A significant relation between the breath and ambient $\mathrm{CO}$ levels in the smokers was also found $(r=0.430, p<0.001)$ (fig 2). Inspection of the regression line of fig 2 reveals that for any one level of ambient $\mathrm{CO}$ the breath level was usually much higher than in the nonsmokers. However, when the smokers in rooms with potential $\mathrm{CO}$ generating heating appliances were excluded from the analysis, there was no correlation between breath and ambient $\mathrm{CO}$ $(\mathrm{n}=37, \mathrm{r}=0.058, \mathrm{NS})$.

Although it is apparent that the type of heating can markedly influence the ambient $\mathrm{CO}$ in a home, analysis of the results in environments where non $\mathrm{CO}$ generating heating devices were in operation showed that smokers do also contribute to the ambient $\mathrm{CO}$. In the non $\mathrm{CO}$ generating rooms of the nonsmokers, there were no values above $4 \mathrm{ppm}$, whereas in similar rooms of smokers $21 \%$ of the values were above $4 \mathrm{ppm}$ with a range of $0-16 \mathrm{ppm}$, and this difference was significant for the rooms of all smokers $\left(\chi^{2}=4.613, p<0.05\right)$ and particularly for those of heavy smokers (20 or more cigarettes per day) compared with those of nonsmokers $\left(\chi^{2}=12.45\right.$, $\mathrm{p}<0.001$ ).

There was a significant correlation between the $\mathrm{CO}$ levels in the breath of smokers in a non $\mathrm{CO}$ generating environment and their reported daily consumption of cigarettes $(n=37, r=0.582$, $\mathrm{p}<0.01$ ). However, a similar relation did not exist among smokers in rooms where potential $\mathrm{CO}$ generating heating systems were in operation $(\mathrm{n}=31, \mathrm{r}=0.033, \mathrm{NS})$. These smokers were found to have significantly elevated breath levels in relation to their daily consumption of cigarettes compared with the previous group $(t=2.4145, p<0.025)$, thus indicating that heating systems and cigarette smoking were both contributing to their breath $\mathrm{CO}$.

\section{Discussion}

Although it has been found ${ }^{12}$ that the measurement of expired breath $\mathrm{CO}$ is a useful way of discriminating between smokers and nonsmokers, these previous studies were carried out on subjects undergoing a medical examination at a BUPA clinic where the ambient $\mathrm{CO}$ level was no higher than the normally expected value of 3 ppm. ${ }^{2}$ It can be assumed that a considerable period of time had elapsed between the subjects leaving home or their place of work and being tested at the clinic, and that therefore equilibration between the carboxyhaemoglobin and the ambient $\mathrm{CO}$ at the clinic had taken place. ${ }^{5}$ In the present study, however, measurements took place in the living rooms of the respondents' homes, where many of the ambient $\mathrm{CO}$ levels far exceeded the expected ceiling level of $3 \mathrm{ppm}$. Although a proportion of the excess $\mathrm{CO}$ was, in the case of smokers, contributed by their own cigarettes (fig 2), a far greater amount was contributed by the $\mathrm{CO}$ generating heating systems. It must be acknowledged that some of the excess $\mathrm{CO}$ may have come from other (particularly heavy) smokers in the household, but data were not collected in these pilot surveys on the smoking habits of other members of the household.

The observation that radiant gas fires, open coal and wood fires, coal and wood stoves, and portable paraffin and gas heaters in use in the room at the time the $\mathrm{CO}$ measurements were made were associated with elevated $\mathrm{CO}$ levels is particularly disturbing in view of the trend back towards open fires and stoves, and of the current emphasis on double glazing and efficient draught exclusion. Without adequate ventilation, the products of combustion remain in the room. High levels of $\mathrm{CO}$ indicate that combustion was incomplete, and observations at the time the measurements were made revealed that with the radiant gas fires, at least, the ambient $\mathrm{CO}$ levels were highest when these appliances were turned down low, particularly if they were of the older type where the elements, when the fire is turned down, are no longer incandescent.

It has been suggested that moderately elevated blood carboxyhaemoglobin levels, an average of $5 \cdot 1 \%, 6$ derived from cigarettes or the environment are associated with disease. ${ }^{46}$ The breath $\mathrm{CO}$ levels in the nonsmokers in this study in rooms with $\mathrm{CO}$ generating heating operating, ranging from 6 to $42 \mathrm{ppm}$, would be expected to reflect carboxyhaemoglobin levels from about $1 \%$ to $7 \%$ in these subjects. This suggests that such nonsmokers may also be at risk from cardiovascular disease and indicates that means should be found to ensure complete fuel combustion or more efficient ventilation of heating appliances. Although extensive double glazing and draught proofing have been introduced to conserve heat, in Sweden this has been accompanied by fitting ducted ventilation systems, forcing the escaping warm air over heat exchangers to heat the incoming air. 
We are grateful to our colleagues in the Office of the Regius Professor of Physic, Dr M Wadsworth, and medical students of the University of Bristol for their assistance in the collection of the data.

\section{References}

${ }^{1}$ Cohen SI, Perkins NM, Ury HK, Goldsmith JR. Carbon monoxide uptake in cigarette smoking. Arch Environ Health 1971; 22: 55-60.
${ }^{2}$ Wald NJ, Idle M, Boreham J, Bailey A. Carbon monoxide in breath in relation to smoking and carboxyhaemoglobin levels. Thorax 1981; 36: 366-9.

${ }^{3}$ Cole PV. Comparative effects of atmospheric pollution and cigarette smoking on carboxyhaemoglobin levels in man. Nature 1975; 255: 699-701.

${ }^{4}$ Borland C, Chamberlain A, Higenbottam T, Shipley M, Rose G. Carbon monoxide yield of cigarettes and its relation to cardiorespiratory disease. $\mathrm{Br}$ Med $J$ 1983; 287: 1583-6.

${ }^{5}$ Ringold A, Goldsmith JR, Helwig HL, Finn R, Schuette F. Estimating recent carbon monoxide exposures. Arch Environ Health 1962; 5: 308-18.

${ }^{6}$ Clyne C, Arch PJ. Nicotine, carbon monoxide and heart disease. Lancet 1981; ii: 1044-5. 